\title{
Investigation of Electrical Defects arising from Excessive Sidewall Force and Excessive Tensile Strain on Power Cables
}

\author{
Darren McConnon \\ Technological University Dublin, darren.mcconnon@mydit.ie \\ Joseph Kearney \\ Technological University Dublin, joseph.kearney@tudublin.ie \\ Tom Looby \\ ESB Networks, Tom.Looby@esb.ie
}

See next page for additional authors

Follow this and additional works at: https://arrow.tudublin.ie/engscheleart

Part of the Electrical and Electronics Commons, Engineering Mechanics Commons, Mechanics of Materials Commons, and the Power and Energy Commons

\section{Recommended Citation}

McConnon, D., Kearney, J., Looby, T. \& O'Shaughnessy, J. (2017) Investigation of Electrical Defects arising from Excessive Sidewall Force and Excessive Tensile Strain on Power Cables, 52nd International Universities Power Engineering Conference (UPEC), Crete, 2017.

This Conference Paper is brought to you for free and open access by the School of Electrical and Electronic Engineering at ARROW@TU Dublin. It has been accepted for inclusion in Conference papers by an authorized administrator of ARROW@TU Dublin. For more information, please contact arrow.admin@tudublin.ie, aisling.coyne@tudublin.ie,gerard.connolly@tudublin.ie.

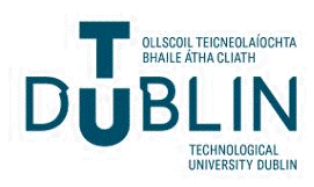


Authors

Darren McConnon, Joseph Kearney, Tom Looby, and James O'Shaughnessy

This conference paper is available at ARROW@TU Dublin: https://arrow.tudublin.ie/engscheleart/261 


\section{Investigation of Electrical Defects arising from Excessive Sidewall Force and Excessive Tensile Strain on Power Cables}

\author{
Darren J. McConnon \\ Dublin Institute of \\ Technology, Ireland \\ darren.mcconnon@mydit.ie
}

\author{
Dr Joseph Kearney \\ Dublin Institute of \\ Technology, Ireland \\ joseph.kearney@dit.ie
}

\author{
Tom Looby \\ ESB Networks, \\ Ireland \\ tom.looby@esb.ie
}

\author{
James O'Shaughnessy \\ ESB Networks, \\ Ireland \\ james.oshaughnessy1@esb.ie
}

\begin{abstract}
The study includes a comprehensive review of the existing literature and guidelines regarding the effects of sidewall force and tensile strain on power cables during installation. The most appropriate diagnostic test methods required to analyse these effects are also assessed. The results of tests and analysis of the existing literature are then combined in an attempt to determine a realistic basis for guidelines and recommendations relevant to cable installation forces.
\end{abstract}

Index Terms-Cable, Compressive, Defect, Discharge, Electrical, Force, Installation, Sidewall, Strain, Tensile.

Introduction

To critically examine the true condition of a distribution power cable, many factors must be taken into consideration before any conclusions can be drawn. A single factor such as the age of the power cable is not sufficient to allow organisations to make decisions on whether or not to replace the cable. Many sources of data are required in order to use complete condition-based decisions and maintenance of the power distribution system and to utilise relatively expensive equipment in the most cost-effective fashion.

This study requires a critical review of the existing literature and guidelines regarding the influence of the strain and force experienced by a cable during installation in a duct or in an underground trench over rollers. The various electrical defects that can arise due to excessive tensile strain, sidewall loading and compressive forces are to be investigated. The standardised diagnostic test methods available are then to be reviewed with the aim of providing guidelines on the most appropriate methods for diagnosing electrical defects as a result of damage to the structure and integrity of the cable during the installation process.

Cable samples are then to be subjected to conditions where the recommended values of tensile strain and sidewall force are exceeded, before completing high voltage electrical testing of the cable samples to determine the effect of these strains and forces. Various high voltage diagnostic methods are to be utilised such as partial discharge and dissipation factor testing.

Finally, a critical examination of the results is to be performed and a number of guidelines and recommendations are to be established, which are to be based on the results and findings of this comprehensive study.

\section{Strains, Forces \& ElectricAl DeFECTS}

The maximum allowable pulling force and the sidewall pressure, particularly at bends, are two characteristics that must be respected when installing power cables in ducts in order to avoid irreversible damage to the cable's electrical properties. However, pulling forces can differ even for identical cable and duct types because of the geometry changes for each separate underground cable system. Large tensile force can develop during cable installation, particularly when being pulled around bends due to frictional forces and the tension multiplication effect. If the coefficient of friction is high, an enduring strain could even persist after the installation is completed, as each component of the cable would have been subjected to a high level of strain.

The ABB standard [1] specifies the maximum pulling force is dependent on the conductor material, which primarily experiences the tensile forces during pulling. The standard specifies the maximum tensile force for both copper and aluminium conductors:

> 30-40 N/mm $\mathrm{mm}^{2}$ (or $3-4 \mathrm{~kg} / \mathrm{mm}^{2}$ ) for aluminium conductor power cables

> $50-70 \mathrm{~N} / \mathrm{mm}^{2}$ (or $5-7 \mathrm{~kg} / \mathrm{mm}^{2}$ ) for copper conductor power cables

The tensile forces that can develop during cable installation are experienced primarily by the conductor and to a secondary degree by the metallic screen or earth wires. Most MV and HV power cables have a large conductor that can endure the load without defect or exorbitant expansion. In fact, excessive extension of the conductor is a serious issue if it were to occur as a strain, as it would likely be placed on the metallic screen or earth wires, which are generally unable to endure a large tensile load.

A sidewall force is subjected to the power cable where it is in contact with the duct wall or rollers during a cable pull. The conductor generates axial and sidewall forces. The power cable moves along the outside of the duct wall if it is a compressive force, but it moves along the inside of the wall if it is a tensile force. As a result of the sidewall force, the cable insulation and jacket are in compression. A non-linear distribution of the force is developed by the existence of 
friction on the bend. The sidewall pressure can be simply given as [2]:

$$
S W P=T / R
$$

Where: $\quad S W P=$ sidewall pressure $(\mathrm{N} / \mathrm{m})$

$T=$ pulling tension $(\mathrm{N})$

$R=$ radius of bend $(\mathrm{m})$

Sidewall crushing, tensile shear and abrasion forces in a straight section of duct are low in comparison to the forces experienced in a bend section of duct, which can be as high as 500 times the forces subjected in a straight section [3]. Ultimately, bends in ducts have higher friction and require smooth curves with large bending radii. The recommended maximum value sidewall force is provided in the AEIC's CG5 Standard 'Underground extruded power cable pulling guide' as $30 \mathrm{kN} / \mathrm{m}$ (or $3000 \mathrm{~kg} / \mathrm{m}$ ) for installation of XLPE insulated cables [4]. This standard outlines the tests adopted in order to arrive at this value.

There are also requirements outlined for the use of rollers. It is recommended that for straight cable runs, a roller is placed every $2.5 \mathrm{~m}$ approximately [3]. This is to prevent the cable sagging and being damaged against concrete or metallic supports. However, where rollers and sidewall pressure on cables are concerned, the major issue is radial force not abrasion. Rollers must be installed to minimise the radial pressure on the cable and adhere to the minimum bend radius. Skid plates are also a viable option as they replicate a duct with regards to providing a sufficient bearing surface. The recommended minimum diameter of rollers is $50 \mathrm{~mm}$ [3].

\section{Diagnostic Methods}

Traditionally, the adopted approach to evaluating electrical power cables in industry was by Direct Current (DC) diagnostic testing, primarily due to the ease of operation, portability of test equipment and low cost in comparison to other methods. Leakage current, insulation resistance and polarisation index were traditionally determined using DC based diagnostic testing methods. In IEEE 400-2001, the significance of the results obtained by these methods is questioned: "The value of the (DC) test for diagnostic purposes is limited when applied to extruded insulations" [5]. This is due to the distribution of electrical stresses differing dependent on whether the cable is subjected to normal inservice Alternating Current (AC) loading or is under Direct Current (DC) test.

Another diagnostic method that is used to evaluate the quality of power cable insulation is Dissipation factor (also known as loss angle, or more commonly referred to as $\tan \delta$ ). Under ideal conditions, a power cable is in essence a long coaxial capacitor [2]. In an ideal capacitor, the current leads the voltage by $90^{\circ}$ (i.e. the current and voltage are $90^{\circ}$ out of phase). However, water trees, moisture and voids are extremely common in service-aged (non-ideal) power cables, causing an increase in resistive current through the cable's insulation. Under these non-ideal conditions, the resultant phase shift between the current and voltage is less than $90^{\circ}$ as the dielectric no longer simulates the ideal capacitor.

Differences in the distribution of electrical stress within the dielectric of a power cable often culminate in localised electrical discharges that partly traverse the dielectric material between the conductor and the earthed ground. This can occur when the limits of the cable are overstressed during rigorous testing or under high loading in service, but somewhat more worryingly, it can also begin as a minor, virtually undetectable issue, and evolve and mature gradually into eventual complete failure of the power cable.

Thus, Partial Discharge (PD) is where a defective section of the dielectric of a power cable, with a large quantity of the $\mathrm{AC}$ voltage distributed across it, then conducts and the rising voltage is distributed across the outstanding region of the insulation. Time domain analysis is generally used in order to determine the location of occurrence of PD [6].

\section{APPLyING EXCESSIVE STRAIN \& SiDEWALl ForCES}

The MV cable type used throughout testing in ESB Networks, Leopardstown, Dublin, Ireland was the $20 \mathrm{kV}$ Waskönig \& Walter single core cable consisting of a 1 x 185 $\mathrm{mm}^{2}$ aluminium solid conductor and a $25 \mathrm{~mm}^{2}$ copper screen with XLPE insulation. The cable is designed for permanent installation directly in the ground, in ducts or in water. The minimum permissible bending radius for this cable type is 15 times the overall diameter of the cable [1].

Tensile stress was applied to cable samples in the ESB Networks test facility through a simplistic method. The aim was to minimise the effect of sidewall loading so no bends or steel ropes were included in the design. One end of the cable sample was anchored to a stationary wooden pole stub using pole slings, shackles and a pulling stocking, and the cable was subjected to a straight pulling operation through the use of a JCB digger.

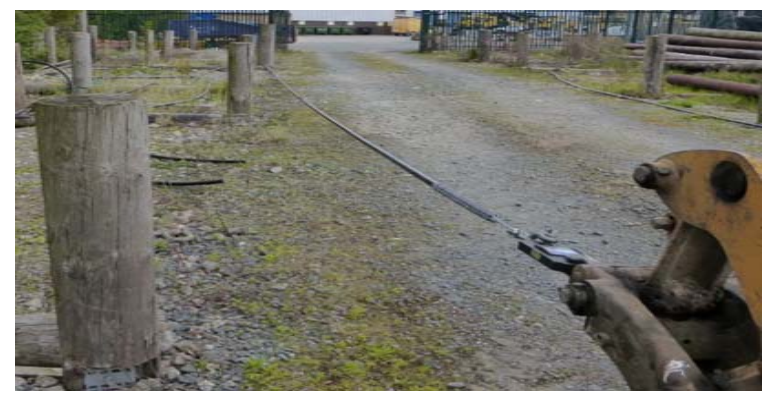

Fig. 1. Tensile Strain Test - Three cable samples were pulled to different tensile strains i.e. $700 \mathrm{~kg}, 1500 \mathrm{~kg}$ and $2000 \mathrm{~kg}$ 
For each of the three tensile pulling forces applied $(700 \mathrm{~kg}$, $1500 \mathrm{~kg}$ and $2000 \mathrm{~kg}$ ), there was $0 \mathrm{~mm}, 10 \mathrm{~mm}$ and $20 \mathrm{~mm}$ cable extension measured respectively during the pulling operation. It should be noted that a period of approx. 2 hours was left prior to terminating each cable sample.

A test method was designed to subject cable samples to sidewall force. The aim of this test was to simulate a trench pulling operation over rollers, with an additional wooden pole stub acting as rollers at a bend in a trench. It can be difficult to isolate the cause of a cable failure, whether that be tensile or sidewall force, when conducting this type of test. However, this arrangement provides for an assessment of how both forces combine to result in the severe strain experienced by a cable in a typical cable pull. In this test arrangement, $700 \mathrm{~kg}$, $1500 \mathrm{~kg}$ and $2000 \mathrm{~kg}$ were applied to three different cable samples at a bend angle of $75^{\circ}$ for each test, with a contact surface with the pole stub of $110 \mathrm{~mm}, 130 \mathrm{~mm}$ and $130 \mathrm{~mm}$, respectively.

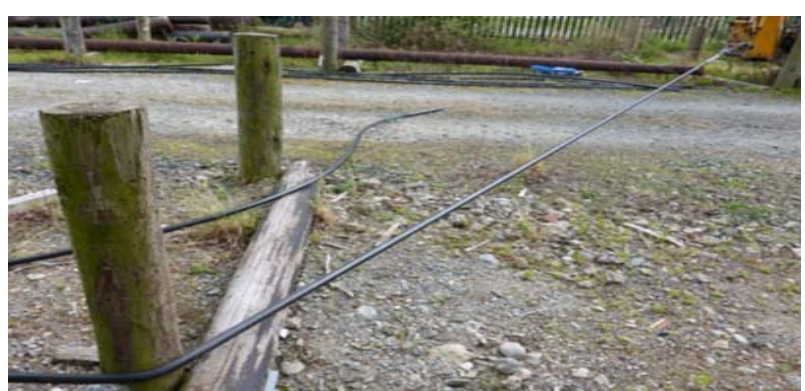

Fig. 2. Sidewall Loading Test - Cable sample is experiencing a tensile strain and sidewall force at the $75^{\circ}$ bend angle

A compressive force test was designed and performed in the Dublin Institute of Technology (DIT) Bolton Street campus, Dublin, Ireland. Initially, two steel rectangular blocks were placed on either side of the longitudinal section of the each cable sample and the cable was compressed. Two different cable samples were tested, one at a force of 1500 $\mathrm{kg} / \mathrm{m}$ and the other at a force of $3000 \mathrm{~kg} / \mathrm{m}$ [4], which were then to be terminated and tested at high voltage.

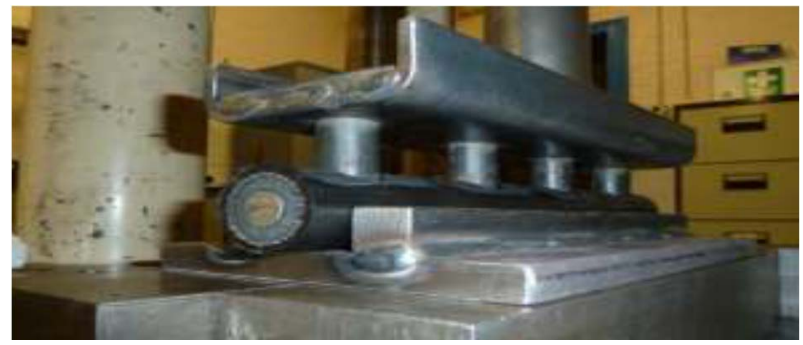

Fig. 3. Compressive Force Test - Rig designed so all force transmitted to the conductor via vertical prongs having drilled the cable at intervals

A rig was also designed that equally distributed the radial compressive force applied. In this arrangement, there was no squashing outward of the cable, because it was held inwards, and all of the force was transmitted to the conductor via vertical prongs that rested on the conductor, having drilled the cable at intervals to receive them.

\section{Results of High Voltage Testing}

Having applied excessive tensile strain, sidewall loading and compressive force to the various cable samples, there was then a requirement to test for electrical defects using high voltage test methods.

TABLE I

LEVEl of ForCe APPLIED TO CABLE SAMPLES

\begin{tabular}{|c|c|c|c|}
\hline $\begin{array}{c}\text { Cable } \\
\text { Sample No. }\end{array}$ & $\begin{array}{c}\text { Tensile } \\
\text { Force (kg) }\end{array}$ & $\begin{array}{c}\text { Bend } \\
\text { Angle }\left({ }^{\circ}\right)\end{array}$ & $\begin{array}{c}\text { Compressive } \\
\text { Force (kg/m) }\end{array}$ \\
\hline 1 & 700 & 0 & - \\
\hline 2 & 1500 & 0 & - \\
\hline 3 & 2000 & 0 & - \\
\hline 4 & 700 & 75 & - \\
\hline 5 & 1500 & 75 & - \\
\hline 6 & 2000 & 75 & 3000 \\
\hline 7 & - & - & \\
\hline 8 & - & - & \\
\hline
\end{tabular}

The IEC 60270 standard outlines the Conventional PD detection method [7], which was employed in this study of partial discharge. The presence of partial discharge causes voltage or current pulses in the power cable and the working principle of the detection method is thus to measure the charge displacement $q$ produced by the voltage or current pulses. This method employs the use of a coupling device, a transmission system and a measuring instrument in order to detect PD presence in the power cable. The noise blocking filter reduces background noise from the HV supply.

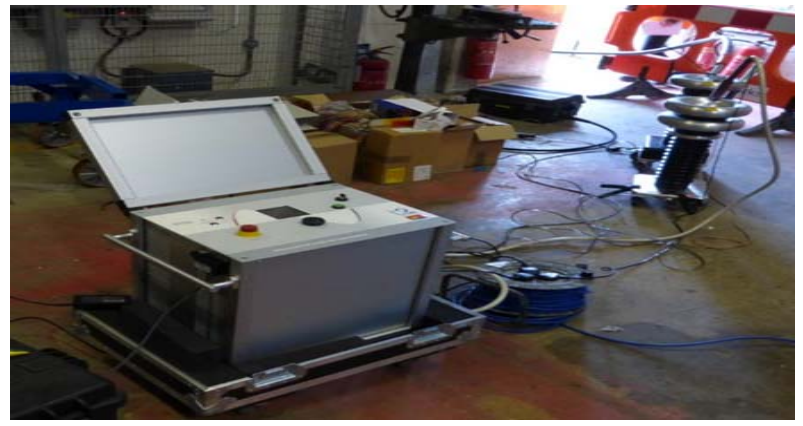

Fig. 4. Partial Discharge and Tan $\delta$ Test - Mechanically stressed cables undergo high voltage defects diagnostic tests

A high voltage (HV) very low frequency (VLF) system provided by b2 electronics operating at $0.1 \mathrm{~Hz}$ was used to complete the measurements in ESB Networks, Leopardstown. Three different levels of voltage were applied to the cable, with measurements completed at $11.5 \mathrm{kV}, 23 \mathrm{kV}$, and finally 
$3 \times U_{o}(34.5 \mathrm{kV})$ root-mean-square $(\mathrm{RMS})$. The final test voltage was three times the nominal voltage $\left(U_{o}\right)$ of the $20 \mathrm{kV}$ MV power cable under test. However, despite further analysis of the results of the tests, no partial discharge above the noise floor of $50 \mathrm{pC}$ was detected. By removing a section of the outer sheath, it was observed that the excessive pulling and sidewall loading had failed to damage the cable in so far as embedding the screen wires in the outer semi-conductive layer.

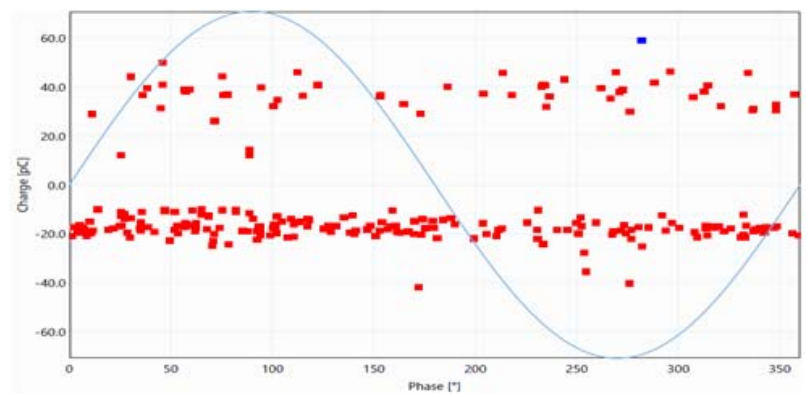

Fig. 5. Partial Discharge Pattern - Noise Floor of $50 \mathrm{pC}$ observed during the combined partial discharge and $\tan \delta$ tests in ESB Leopardstown

Despite no detection of partial discharge, there was significant corona noise at the far end of the cable, which was affecting results, but this was resolved by fitting a corona shield. An interesting observation was that the corona discharge was only present near the peak of the positive half cycle. However, following the fitting of the corona shield, there was no evidence of corona discharge.

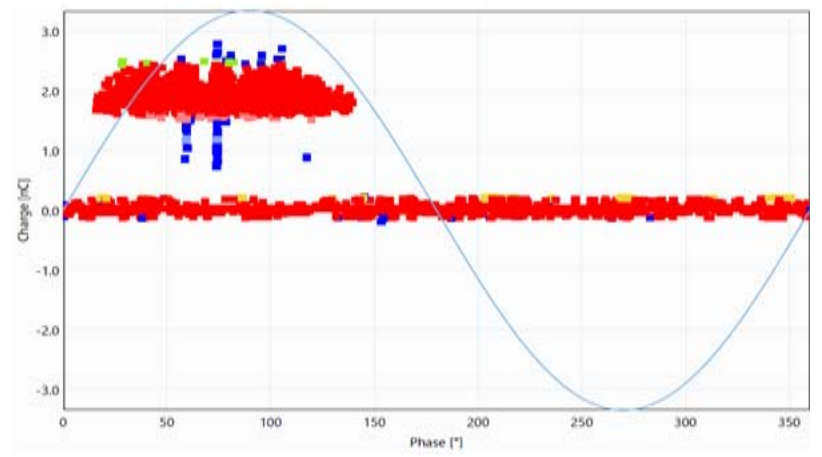

Fig. 6. Corona Discharge Observed on Positive Half Cycle - Corona Discharge eliminated through fitting of corona shield

The cable samples subjected to excessive tensile strain and sidewall loading, including the samples tested using the compressive force test arrangement, were subsequently tested in PowerCSL test facilities, Kent, UK. In this test facility, high voltage can be applied in a noise free environment. Four times the nominal voltage was applied for a period of four hours to each cable sample $\left(4 \times U_{o}\right.$ for 4 hours).

The noise floor was $2 \mathrm{pC}$, as opposed to $50 \mathrm{pC}$ encountered during the combined partial discharge and tan $\delta$ testing completed in ESB Networks, Leopardstown. There was a constant partial discharge level for each of the cable samples tested with constant applied voltage of $46 \mathrm{kV}\left(4 \times U_{o}\right)$.

For example, there was a PD level of $10 \mathrm{pC}$ at $48 \mathrm{kV}$ for the cable sample with $3000 \mathrm{~kg} / \mathrm{m}$ applied during the compressive force test. However, there was no significant partial discharge observed that would indicate cable failure despite the increase in voltage and application time in PowerCSL test facilities, thus the cable samples passed the various tests.

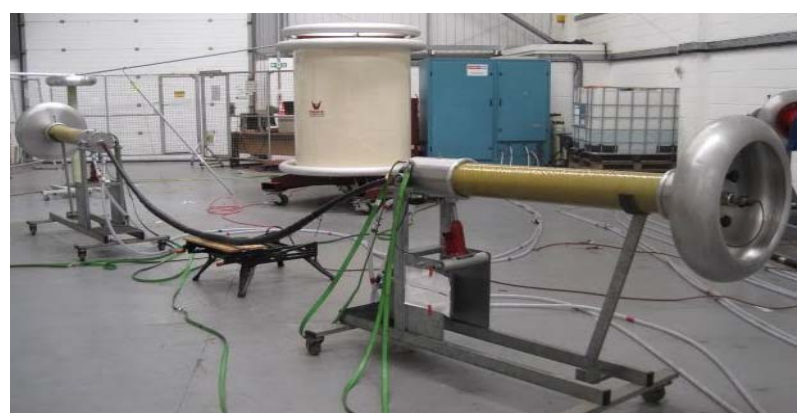

Fig. 7. Test arrangement in PowerCSL - Four times the nominal voltage applied to cable samples for four hours during Noise Free PD test

The screen wires were deliberately protruded into the insulation of the cable sample that had been subjected to a pulling force of $1500 \mathrm{~kg}$ and sidewall loading. This was completed as an attempt to mimic a condition that could occur in a real world scenario where the cable experienced excessive tensile strain and sidewall loading during installation and was then subjected to normal operating conditions over years in service. An electrode was effectively created by protruding the screen wires slightly into the cable insulation. With the cable in this condition, there was significant partial discharge observed.

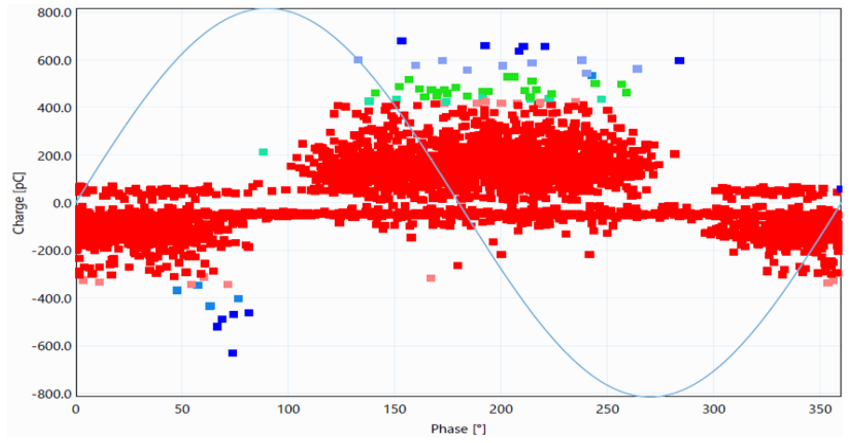

Fig. 8. Partial Discharge Observed - Screen Wires protruded into insulation to mimic effects due to excessive strain

It is possible to distinguish between the two types of discharge observed in the experimental results of the tests completed in ESB Networks test facility. Surface discharge (generally simply referred to as partial discharge) and corona discharge have different characteristics and as such can be analysed through the PD phase angle patterns obtained. 
Partial discharge is capacitive in nature so as was expected, the partial discharge occurred near the zero crossings and where the voltage was undergoing most change, as the partial discharge was out of phase with the voltage. However, since many capacitive-like characteristics occur together, there is a complex phasor sum phenomenon and a stream of partial discharge is observed across the voltage waveform either side of the zero crossing.

Corona discharge on the other hand only occurs when the electric field surrounding the live conductor attracts the free electrons in the air during the positive half cycle and when the electric field increases to such a level that local ionisation can occur. Therefore, the voltage needs to exceed a certain threshold for corona discharge to occur and the inherently negative free electrons in the air are only attracted to the live conductor during the positive half cycle.

The $\tan \delta$ test was simultaneously completed on the cable sample subjected to a pulling force of $1500 \mathrm{~kg}$ and sidewall loading. The loss angle was observed to have increased with when partial discharge was occurring. For paper insulated cables, the tangent of the loss angle could be as high as 30 , but is a lot lower for XLPE insulated cables, as observed in this test completed in ESB Networks, Leopardstown with a $\tan \delta$ value between 0.00195 and 0.00225 .

The value is observed to increase as the capacitance of the cable deviates due to surface discharges, voids etc. which are resistive in nature. Also illustrated is that the susceptibility of a cable to partial discharge, and similarly the $\tan \delta$ value, increase with voltage.

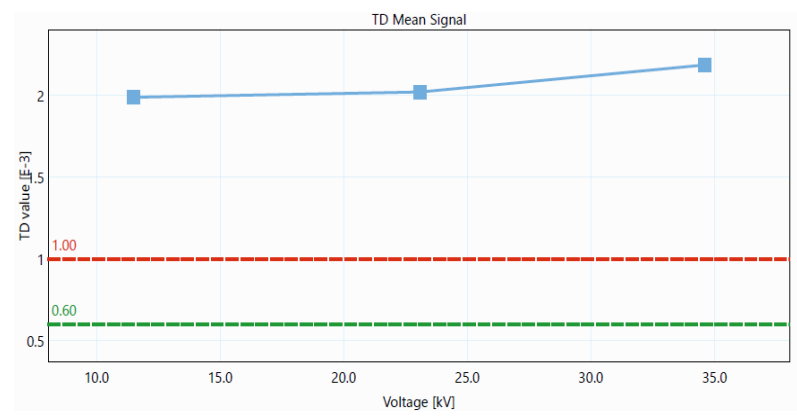

Fig. 9. Dissipation Factor $(\tan \delta)$ Test - the $\tan \delta$ value was observed to have increased with an increase in voltage and the occurrence of PD

\section{CONCLUSION}

Among the most beneficial techniques to determine the effects of excessive tensile strain and sidewall loading are the partial discharge diagnostic methods. When an assessment procedure combines both dissipation factor $(\tan \delta)$ and partial discharge methods, the data obtained has greater reliability and accuracy on the condition of both the cable itself and associated cable accessories such as joints and terminations. Identifying weak points or damage to cables can assist in preventing complete breakdown of insulation leading to costly repair of the distribution network and power outages for both utility and customer.

The results of the testing completed in ESB Leopardstown demonstrate that subjecting cables to excessive tensile and sidewall forces is not sufficient to lead to significant partial discharge in the short-term. However, the long-term effects of placing an excessively strained cable in operation where a large current flows for an extended period of time are yet to be explored. As evidenced by this investigation, partial discharge can be identified and measured through various test methods. However, the capability to accurately mimic the conditions experienced by a cable in-service having undergone excessive tensile strain and sidewall loading is an essential component of testing newly manufactured cables.

It is recommended to test other insulation materials as this investigation primarily focused on XLPE insulation. The diagnostic methods should also be applied to insulation such as ethylene propylene rubber (EPR) and paper insulations. Insulation breakdown performance and reliability of diagnostic methods for each type should be further assessed.

It is also recommended that further research is completed into performing heat cycling to validate and improve on the results obtained through this investigation. During heat cycling, current is allowed to flow through the cable system under test until sufficiently intense heat is obtained. A predetermined time duration is then observed, in which time the cable will cool naturally, prior to initialising subsequent current flow. It would interesting to observe if insulation breakdown would occur under these conditions, as these tests use accelerated aging to mimic the effects on a cable subjected to years of normal operating conditions in service, albeit performing the tests over a shorter period of time.

\section{REFERENCES}

[1] ABB, XLPE AC Land Cable Systems, User Guide, Revision 5. ABB, 2GM 5007, GB rev5, Feb. 2010.

[2] W.A. Thue, Electrical Power Cable Engineering: Third Edition. Florida, USA: CRC Press, Taylor \& Francis Group, 2012, pg. 124.

[3] EA Technology, "Cable Laying and Sidewall Pressure," unpublished. Presented at EA Technology Cable Engineers' Forum, Capenhurst, UK Oct. 2016.

[4] AEIC, Underground extruded power cable pulling guide, Third Edition. AEIC Std. CG5, Jan. 2015.

[5] IEEE Guide for Field Testing and Evaluation of the Insulation of Shielded Power Cable Systems, IEEE Std. 400-2001, Apr. 2002.

[6] IEEE Guide for Partial Discharge Testing of Shielded Power Cable Systems in a Field Environment, IEEE Std. 400.3-2006, Jun. 2006

[7] IEC Standard for High-voltage test techniques - Partial discharge measurements, IEC 60270:2000+AMD1:2015 CSV, Nov. 2015. 